\title{
A Heuristic for Group Scheduling the Multi-stage Hybrid Flow Shop Problems
}

\author{
R. Franklin Issac, R. Saravanan, R. Pugazhenthi and R. Raju
}

\begin{abstract}
According to the practical relevance, the Hybrid Flow Shop (HFS) has attracted many researchers recently. This paper addresses a special case of group scheduling problem in a multi-stage HFS with optimization of throughput related objectives. The aim of the work is to simplify the solution procedure through a heuristic approach to reach the optimal solution, i.e., minimal makespan with optimal flow parameters. The heuristic solution was tested with all possible group schedules encountered in the HFS problem to ensure the compatibility of the optimal solution and its consistency with the throughputs. The throughput related measures other than makespan such as queue status and machine utilization were considered to evaluate the performance of the heuristic. The heuristic performs well to reach the optimal solution with minimal makespan and queue status with effective machine utilization. A case study was done in a pulley manufacturing plant and a global solution was suggested.
\end{abstract}

Keywords--- Scheduling, Heuristics, Simulation, Mathematical Model, Hybrid Flow Shop.

\section{INTRODUCTION}

$\mathrm{T}$ HE Hybrid Flow Shop (HFS) problems have attracted a lot of researchers due to its practical relevance, but still the complexity remains in the optimization of scheduling. The HFS problems are quite common in practice, especially in process industries like electronics industry, paper industry, textile industries, Concrete, photographic film applications and other industrial applications where multiple servers (machines) are available at each stage as well as in certain flexible manufacturing environments [1-5].

Riane et al [6] developed an effective heuristic approach to minimize the makespan of an HFS with three stages. Even though the makespan minimization is the primary objective of any shop floor, the optimization of flow parameters is also essential [7]. Since, the flow parameters can directly affect the primary objective and down the efficiency of the schedule.

In modern HFS, the jobs are considering to process with bulky lot size and types to meet the market demand. Karimi and Seyedhoseini [8] inferred that the lot size may influence

R. Franklin Issac, Department of Mechanical Engineering, Anna University, Chennai. E-mail:franklin.0508@gmail.com

R. Saravanan, Professor, Department of Mechanical Engineering, Vels University, Chennai.

R. Pugazhenthi, Professor, Department of Mechanical Engineering, Vels University, Chennai.

R. Raju, Professor \& Head, Department of Industrial Engineering, Anna University, Chennai.

DOI:10.9756/BIJIEMS.7623 on group scheduling in shop floor, so a cutting plane approach was proposed. Apart from this many evolutionary approaches were developed to optimize the flow parameters.

Ashkan and Jeffrey [9] suggested the simulation was the optimal tool to minimize the makespan of the HFS problems even at dynamic environment and it is agreed with the results of Azadeh et al. [10] and Kun et al. [11].

Mir and Rasaratnam [12] suggested the group scheduling was a better approach to minimize the demerits of HFS scheduling with practical feasibility. According to Fardin and Parmis [13], to reach a minimal makespan along with optimal flow parameters through group scheduling was a tedious process. Since, finding a best group in $\sum_{\mathrm{r}=1}^{\mathrm{N}-1} \mathrm{~N} ! /(\mathrm{N} *(\mathrm{~N}-\mathrm{r})$ !) possibilities was a tough task even through simulation.

In this research, a simple heuristic approach is proposed to identify the optimal group and its size, which can provide optimal flow parameters with minimal makespan. The performance of the heuristic was studied and validated through simulation results. The proposed heuristic is implemented in a pulley manufacturing plant (case study) to suggest a global solution.

\section{HEURISTIC APPROACH}

A heuristic approach is developed to find the best groups for LEVEL I and II scheduling problem in a simple manner. The steps involved in the heuristic are described below.

Step 1: Calculate the cumulative processing time of each job type $\left(\boldsymbol{P}_{i}\right)_{J l}$ by using equation (1).

$$
\left(\mathrm{P}_{\mathrm{i}}\right)_{\mathrm{Jl}}=\sum_{\mathrm{j}=1}^{\mathrm{M}} \mathrm{PT}_{\mathrm{ij}}
$$

Step 2: Calculate the total processing time of all the jobs type TP by using equation (2).

$$
\mathrm{TP}=\sum_{\mathrm{i}=1}^{\mathrm{X}}\left(\mathrm{P}_{\mathrm{i}}\right)_{\mathrm{Jl}}
$$

Step 3: Check the condition to apply whether the group scheduling is required or not through the equation (3). If the condition is true, the group scheduling approach is not feasible.

$$
\left(\mathrm{P}_{\mathrm{i}}\right)_{\mathrm{Jl}} \approx \mathrm{TP} / \mathrm{x}
$$

Step 4: Find the possible groups for better throughputs related measures of performances for each Batch Size (BS) by using the equation (4). 


$$
(T P * x / B S) \approx \sum_{i=1}^{x / B S}\left(P_{i}\right)_{J l}
$$

Where, $B S=1,2,3 \ldots(l-1)$

Condition 1: The relative deviation of $\left(T P^{*} x / B S\right)$ for all batches must be equal else it should satisfy the condition 2 .

Condition 2: The algebraic sum of the relative deviation from $\left(T P^{*} x / B S\right)$ should be equal or the nearly equal to zero.

Step 5: Increase the batch size and repeat the step 4 till BS is equal to $(l-1)$.

Step 6: The identified possible pairs of job types are to be considered to make a batch. The minimum group size along with maximum batch size will contribute majorly to optimize the level II scheduling.

Step 7: Sequence the job type in a batch based on the ascending order of $\left(\boldsymbol{P}_{i}\right)_{J l}$ (i.e., the high priority is for the shortest $\left(\boldsymbol{P}_{i}\right)_{J I}$ to optimize the level I scheduling.

\section{A CASE STUDY-PULLEY MANUFACTURING ENVIRONMENT}

\section{A. HFS Problem Descriptions}

A case study was conducted in pulley production plant with three stages and six types of pulleys (jobs) with the lot size of 200. The pulleys are processed without skipping through lathe, milling and special CNC machines in a uniform sequence and unidirectional job flow with the priority of FIFO. The processing time of each job type through $\boldsymbol{i}^{\text {th }}$ stage is furnished in Table 1. The setup time and transportation time were included in the processing time of the job type.

Table 1: The Processing Time of the HFS Problem

\begin{tabular}{|l|l|l|l|}
\hline Job Type & Stage 1 & Stage 2 & Stage 3 \\
\hline $\mathrm{J}_{1}$ & 1.5 & 5.42 & 4.95 \\
\hline $\mathrm{J}_{2}$ & 4.94 & 2.7 & 4 \\
\hline $\mathrm{J}_{3}$ & 2.9 & 2.86 & 2.7 \\
\hline $\mathrm{J}_{4}$ & 3.94 & 4.22 & 2.5 \\
\hline $\mathrm{J}_{5}$ & 1.94 & 5.86 & 2.4 \\
\hline $\mathrm{J}_{6}$ & 5.1 & 5.98 & 1.6 \\
\hline
\end{tabular}

\section{B. Implementation of Proposed Heuristic}

Step 1: The cumulative processing time of each job $\left(P_{i}\right)_{J 1}$ was calculated using equation (1) i.e., $\left(\mathrm{P}_{1}\right)_{\mathrm{J} 1}=\mathrm{PT}_{11}+\mathrm{PT}_{12}+$ $\mathrm{PT}_{13}=1.5+5.42+4.95=$ 11.87. Similarly, $\left(\mathrm{P}_{2}\right)_{\mathrm{J} 2}=11.64$; $\left(\mathrm{P}_{3}\right)_{\mathrm{J} 3}=8.46 ;\left(\mathrm{P}_{4}\right)_{\mathrm{J} 4}=10.66 ;\left(\mathrm{P}_{5}\right)_{\mathrm{J}}=10.2 ;\left(\mathrm{P}_{6}\right)_{\mathrm{J} 6}=12.68$.

Step 2: The cumulative processing time of all the jobs TP is calculated using equation (2). TP $=\operatorname{Sum}\left(\left(\mathrm{P}_{1}\right)_{\mathrm{J} 1}:\left(\mathrm{P}_{6}\right)_{\mathrm{J} 6}\right)=$ $11.87+11.64+8.46+10.66+10.2+12.68=65.51$.

Step 3: The $(\mathrm{TP} / x)$ is $(65.51 / 6=10.92)$. The $\left(\mathrm{P}_{\mathrm{i}}\right)_{J I}$ is not equal to 10.92 i.e. (TP/x). Therefore, the group scheduling is required.

Step 4: By Substituting BS $=2$ in equation (4), the $\left(T P^{*} x /\right.$ $B S$ ) value obtained is 32.76 , it is possible with the summation of $\left(P_{i}\right)_{J i}$ of jobs $\mathrm{J}_{1}, \mathrm{~J}_{2} \& \mathrm{~J}_{3}$ and also $\mathrm{J}_{4}, \mathrm{~J}_{5} \& \mathrm{~J}_{6}$. The relative deviations of the two batches are +0.79 and -0.78 from 32.76 which are almost equal.
Step 5: Substitute BS $=3$ in equation (4), the $\left(T P^{*} \chi / B S\right)$ value will be 21.84 , it is possible with the summation of $\left(\mathrm{P}_{\mathrm{i}}\right)_{\mathrm{Ji}}$ of jobs $\mathrm{J}_{1} \& \mathrm{~J}_{2}, \quad \mathrm{~J}_{3} \& \mathrm{~J}_{6}$ and also $\mathrm{J}_{4} \& \mathrm{~J}_{5}$. The relative deviations of the three batches are 1.67, -0.75 and -0.98 from 21.84 and the algebraic sum of relative deviations is $0.06 \approx 0$. Even though the condition 1 fails, the condition 2 is satisfied.

Step 6: if BS is 4 in equation (4), the (TP* $x / B S$ ) value will be 16.34, it is not possible with the summation of $\left(\mathrm{P}_{\mathrm{i}}\right)_{\mathrm{Ji}}$ of any job types. Since, the minimum sum of $\left(\mathrm{P}_{\mathrm{i}}\right)_{\mathrm{Ji}}$ is 18.66 so the condition 1 fails and regarding condition 2, the relative deviation is high, therefore the iteration is ended.

Step 6: The identified possible better group schedules are $\left(\mathrm{J}_{1}, \mathrm{~J}_{2} \& \mathrm{~J}_{3}\right)\left(\mathrm{J}_{4}, \mathrm{~J}_{5} \& \mathrm{~J}_{6}\right)$ and $\left(\mathrm{J}_{1} \& \mathrm{~J}_{2}\right)\left(\mathrm{J}_{3} \& \mathrm{~J}_{6}\right)\left(\mathrm{J}_{4} \& \mathrm{~J}_{5}\right)$ for Level II optimization.

Step 7: For Level I optimization, the job type are sequenced as $\left(\mathrm{J}_{3}, \mathrm{~J}_{2} \& \mathrm{~J}_{1}\right)\left(\mathrm{J}_{5}, \mathrm{~J}_{4} \& \mathrm{~J}_{6}\right)$ and $\left(\mathrm{J}_{2} \& \mathrm{~J}_{1}\right)\left(\mathrm{J}_{3} \& \mathrm{~J}_{6}\right)\left(\mathrm{J}_{5}\right.$ $\left.\& J_{4}\right)$ as based on the ascending order of $\left(P_{i}\right)_{J l}$.

\section{Validation of Proposed Heuristic through Simulation}

Table 2: Summary of Group Schedule Results

\begin{tabular}{|c|c|c|c|}
\hline Best Group Sequence & Best Sequence (G) & $\mathrm{C}_{\max }$ & Minimum $\mathrm{C}_{\max }$ \\
\hline 1 & $(1,2,3,4,5,6)$ & 4532 & 4532 \\
\hline 2 & $(1,2,3,5,6)(4)$ & 4539 & \multirow[t]{3}{*}{4539} \\
\hline 3 & $(1,2,3,6)(4,5)$ & 4539 & \\
\hline 4 (Heuristic Solution) & $(1,2,3)(4,5,6)$ & 4541 & \\
\hline 5 & $(1,2,5,6)(3)(4)$ & 4584 & \multirow[t]{3}{*}{4584} \\
\hline 6 & $(4,5,6)(1,2)(3)$ & 4586 & \\
\hline 7 (Heuristic Solution) & $(1,2)(3,6)(4,5)$ & 4586 & \\
\hline 8 & $(4,5,6)(1)(2)(3)$ & 4780 & \multirow[t]{2}{*}{4752} \\
\hline 9 & $(1,3)(2,5)(4)(6)$ & 4752 & \\
\hline 10 & $(4,5)(1)(2)(3)(6)$ & 4788 & 4788 \\
\hline
\end{tabular}

\section{CONCLUSION}

The complexity of multi-stage HFS problems posed by the manufacturing environment had been studied and a new heuristic approach was proposed for group scheduling the HFS problems. The mathematical model was generated and experimented to study a pulley manufacturing environment with group scheduling nature and to find an optimal solution with minimal makespan and optimal flow parameters. It was concluded that the group schedule with batch size lesser or equal to $x / 2$ can provide the global solution. With this type of heuristic approach, the global solution suggested will minimizes the sequencing and scheduling complexity associated with this type of problem posed by the industries.

\section{REFERENCES}

[1] J. Grabowski and J. Pempera, "Sequencing of jobs in some production system”, European Journal of Operational Research, Vol. 125, No.3, Pp.535-550, 2000.

[2] R. Franklin Issac, R. Pearlin Helina, T. Illakiya, S. Chitra, M. Yogalakshmi and M. Ishwariya, "Computational Inverse Branch and Bound Heuristic for Flowshop Problem”, International Journal of Innovative Research in Technology, Science\&Engineering, Vol. 2, No.6, Pp. 65-72, 2016.

[3] S. Bertel and J.C. Billaut, "A genetic algorithm for an industrial multiprocessor flow shop scheduling problem with recirculation", European Journal of Operational Research, Vol. 159, No.3, Pp.651-662, 2004.

[4] A. Allahverdi and F.S. Al-Anzi, "Scheduling multi-stage parallelprocessor services to minimize average response time", Journal of the Operational Research Society, Vol. 57, No. 1, Pp. 101-110, 2006. 
[5] L. Chen, N. Bostel, P. Dejax, J.C. Cai and L.F. Xi, "A tabu search algorithm for the integrated scheduling problem of container handling systems in a maritime terminal”, European Journal of Oper. Research, Vol. 181, No.1, Pp.40-58, 2007.

[6] F. Riane, A. Artiba, and S.E. Elmaghraby, "A hybrid three-stage flowshop problem: efficient heuristics to minimize makespan”, European Journal of Operational Research, Vol. 109, No.2, Pp.321-329, 1998.

[7] R Pugazhenthi, M Anthony Xavior and R Franklin Issac, “Optimization of Makespan Time Associated with Probability Natured Jobs under Critical Machine in a Flow Shop", International Conference on Sustainable Manufacturing.

[8] M. Karimi-Nasab and S.M. Seyedhoseini, "Multi-level lot sizing and job shop scheduling with compressible process times: A cutting plane approach”, European Journal of Operational Research, Vol. 231, No. 3, Pp. 598-616, 2013.

[9] A. Negahban and J.S. Smith, "Simulation for manufacturing system design and operation: Literature review and analysis", Journal of Manufacturing Systems, Vol. 33, No. 2, Pp. 241-261, 2014.

[10] A. Azadeh, S. Motevali Haghighi and S.M. Asadzadeh, "A novel algorithm for layout optimization of injection process with random demands and sequence dependent setup times", Journal of Manufacturing Systems, Vol. 33, No. 2, Pp. 287-302, 2014.

[11] K. Mao, Q.K. Pan, X. Pang and T. Chai, “A novel Lagrangian relaxation approach for a hybrid flowshop scheduling problem in the steelmakingcontinuous casting process”, European Journal of Operational Research, Vol. 236, No.1, Pp.51-60, 2014.

[12] MA Bozorgirad and R. Logendran, "Bi-criteria group scheduling in hybrid flowshops", International Journal of Production Economics, Vol. 38, No. 13, Pp. 599-612, 2013.

[13] Fardin Ahmadizar and Parmis Shahmaleki, "Group-shop scheduling with sequence-dependent set-up and transportation times", Applied Mathematical Modelling, Vol. 38, No.21-22, Pp. 5080-5091, 2014. 